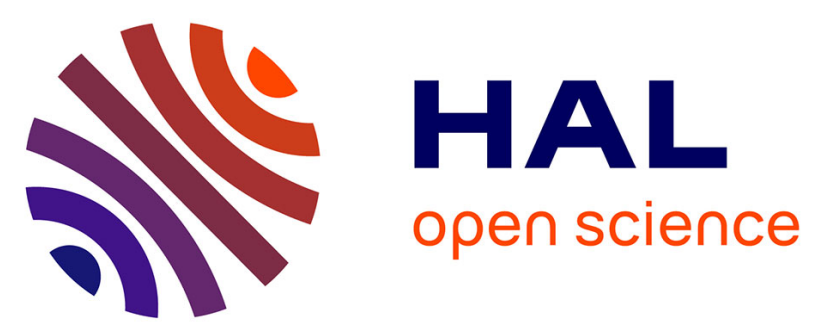

\title{
Call rates of mothers change with maternal experience and with infant characteristics in free-ranging gray-cheeked mangabeys
}

\author{
Malgorzata E. Arlet, Linda-Liisa Veromann, Raivo Mänd, Alban Lemasson
}

\section{- To cite this version:}

Malgorzata E. Arlet, Linda-Liisa Veromann, Raivo Mänd, Alban Lemasson. Call rates of mothers change with maternal experience and with infant characteristics in free-ranging gray-cheeked mangabeys. American Journal of Primatology, 2016, 78 (9), pp.983-991. 10.1002/ajp.22568 . hal01342444

HAL Id: hal-01342444

https://hal-univ-rennes1.archives-ouvertes.fr/hal-01342444

Submitted on 22 Jul 2016

HAL is a multi-disciplinary open access archive for the deposit and dissemination of scientific research documents, whether they are published or not. The documents may come from teaching and research institutions in France or abroad, or from public or private research centers.
L'archive ouverte pluridisciplinaire HAL, est destinée au dépôt et à la diffusion de documents scientifiques de niveau recherche, publiés ou non, émanant des établissements d'enseignement et de recherche français ou étrangers, des laboratoires publics ou privés. 
Call rates of mothers change with maternal experience and with infant characteristics in free-ranging gray-cheeked mangabeys

Małgorzata E. Arlet ${ }^{1,2 *}$, Linda-Liisa Veromann ${ }^{3}$, Raivo Mänd ${ }^{3}$, Alban Lemasson ${ }^{1,4}$

${ }^{1}$ Université de Rennes 1, Ethologie animale et humaine, UMR 6552 - CNRS, Paimpont,

France

${ }^{2}$ School of Biology, Indian Institute of Science, Education and Research Thiruvananthapuram, India

${ }^{3}$ University of Tartu, Department of Zoology, Institute of Ecology and Earth Sciences, Tartu, Estonia

${ }^{4}$ Institut universitaire de France, Paris, France

*To whom correspondence should be addressed: M.E. Arlet, School of Biology, Indian Institute of Science, Education and Research Thiruvananthapuram, India; email: maarlet@yahoo.com

Short title: Maternal Calls in Arboreal Mangabeys 
Arlet et al. p. 2

\section{ABSTRACT}

Studies have shown that becoming a mother triggers important social changes within females, according to both social experience and infant characteristics, showing different maternal concerns. But how this impacts call usage has been far less studied. Based on six months of observations of five free-ranging groups of gray-cheeked mangabeys, we investigated variations in the production of three call types (contact, excitement, and alarm calls) in 29 females of different ages, dominance ranks, and infant rearing experiences: 15 females with infants of different ages and sexes, and 14 females without infants. We found that in females with infants - both maternal and infant characteristics influenced call production in a call type-dependent way. Females produced contact calls at a higher rate during the first month of infant age and after weaning when infants start to move away. Mothers of daughters produced more contact calls than mothers of sons. More excitement calls were recorded for first-time and young mothers and for females with young infants, while alarm call rates were not influenced by any of these factors. Increased mother-infant spatial separation enhanced only contact and excitement call rates. Finally, we found that females with infants vocalized much more than females without infants. Our results contribute to the current debate about the social factors responsible for the flexibility of call usage in nonhuman primates and open new lines for research on mothering behavior in forest-dwelling species.

KEYWORDS: maternal communication, calling rates, maternal age, parity, arboreal primate. 


\section{INTRODUCTION}

Individuals vary in their social behaviors throughout life. In adults, one crucial event associated with marked social changes is when a female becomes a mother [Struhsaker, 1971]. In many primate species this has been found to trigger different maternal behaviors with significant individual variations usually based on non-vocal social criteria [Fairbanks, 1996]. After giving birth, females become stressed to some degree, and sensitive to social interactions and proximities, so that they maintain either protective, restrictive or relaxed bonds with their offspring [Fairbanks, 1996]. These variations are known to be modulated by the mother's social experience [Hinde, 1974; Rosenblum \& Youngstein, 1974; Altmann, 1980; Fairbanks, 1996; Bardi \& Huffman, 2002] and infant characteristics [e.g. Maestripieri, 2005; Hoffman et al., 2010].

Vocal communication is a crucial way to maintain socio-spatial cohesion among group members [Lemasson, 2011]. Call rates in adult female primates are known to be flexible, depending for instance on changes in internal arousal states [Lemasson et al., 2012], social composition of the audience [Townsend et al., 2008], social composition of the group [Silk, 2002], and social status of the interacting partner [Lemasson et al., 2010, 2013]. However, the question remains open with regards to whether or not call usage also varies between different types of mothers.

Several variables and particularly mother's age, dominance rank, and parity status, as well as the infant's age and sex are known to be key factors influencing maternal non-vocal behavior in mammals [e.g. dolphins Tursiops truncatus: Gubbins et al., 1999, African elephant Loxodonta africana: Lee \& Moss, 1999], and notably in primate species [e.g. vervet monkeys Cercopithecus aethiops: Lee, 1984; rhesus monkeys Macaca mulatta: Simpson, 1985; baboons Papio sp.: Nash, 1978, Altmann, 1980; patas monkeys Erythrocebus patas: 
Loy \& Loy, 1987]. However, most primate species studied so far live in very open habitat favoring a visual mode of communication. Thus, we can predict that mothers' and infants' characteristics will similarly influence maternal vocal behavior in primate species better known as vocal communicants such as forest-dwelling species.

The few developmental studies available typically focus on maternal influences on the vocal development of infants [e.g. pygmy marmoset Cebuella pygmaea: Elowson et al., 1992; rhesus macaques Macaca mulatta: Hammerschmidt et al., 2000; chimpanzees: Laporte \& Zuberbühler, 2011; agile gibbons Hylobates agilis: Koda et al., 2013]. Nevertheless, some studies also suggest a vocal adaptation of adults, notably mothers, to the presence and characteristics of infants. For example, infants of vervet monkeys learn the appropriate context of alarm calling through vocal reinforcements by adults [Cheney \& Seyfarth, 1990]. Also, Roush and Snowdon [2001] showed that adult calls associated with food transfer in cotton-top tamarins (Saguinus oedipus) guide infant development of feeding behavior and food-associated calling. Lastly, the acoustic analysis of mother-daughter duets in free-ranging agile gibbons, at different offspring developmental stages, showed that mothers adjust their song pattern to the infant's age by producing a more stereotypic song at early developmental stages, a phenomenon comparable to "motherese" [Koda et al., 2013].

The goal of this study was to investigate the social factors responsible for the variations in maternal vocal communication in an arboreal primate species. Gray-cheeked mangabeys (Lophocebus albigena) are appropriate models for this study for several reasons. First, like most forest-dwelling animals, they rely mainly on calls to communicate [Marler, 1965]. As habitat influences communicative repertoires [Waser \& Brown, 1986], we expect that in the highly diverse, visually dense and three-dimensional environment of arboreal species, vocal communication also plays an important role in maternal care. Second, gray-cheeked mangabeys show strong social similarities to baboons, their savannah relatives who typically 
exhibit maternal behaviors depending on both maternal and infant characteristics [Altmann, 1980]. Hence, they live in complex (i.e. multi-male, multi-female) social groups [Waser, 1977; Henzi \& Barrett, 2002]. In addition, females usually remain in their natal groups throughout life and have stable and linear dominance hierarchies [Chancellor \& Isbell, 2009a], whereas males disperse from their natal groups [Olupot \& Waser, 2001]. Mangabeys are also aseasonal breeders [Wallis, 1983; Olupot \& Waser, 2013; Arlet et al., 2015]. Third, the vocal repertoire of mangabeys has been described and is composed of several discrete (easily identifiable) call types [Chalmers, 1968; Bouchet et al., 2010; Brown, 2014]. The flexibility in acoustic structure is call type-dependent with more intra- and inter-individual variations in affiliative calls, like contact calls, than in non-social calls, like alarm calls [Bouchet et al., 2013]. We can thus expect the same trend for variations in call usage. Fourth, mothers in this species have been found to display different mothering care styles, based on non-vocal data [Arlet et al., under revision].

Thus by observing the vocal behavior of gray-cheeked mangabey females in five freeranging groups, we tested whether their own characteristics (age, rank, and rearing experience) and/or the characteristics of their infants (sex and age) influence emission rates of three functionally different call types (contact call, excitement calls and alarm calls). We predicted that female and infant characteristics will influence contact and excitement call usage, but not alarm calls which are more related to external factors. Finally, we expected that mothers will vocalize more frequently than females without infants to keep contact with the infant, or to interact with other group members typically interested in newborns [Henzi \& Barrett 2001].

\section{METHODS}

\section{Study Area and Subjects}


Data were collected from the end of July 2011 to March 2012 in Kibale National Park, Uganda. Kibale is a $795 \mathrm{~km}^{2}$ moist, evergreen, and medium altitude forest with areas of swampland, grassland, thicket, and secondary forest [Chapman et al., 2010]. We collected observational data on five groups of gray-cheeked mangabeys inhabiting secondary forest: CC, Lower Camp 1 (LC1), Lower Camp 2 (LC2), Butanzi 1 (BT1), and Mikana (MK), which ranged in size from 10 to 25 individuals (i.e. 1-8 adult males, 4-7 adult females, 2-7 offspring). These groups have been exposed to regular observations since 1999 and a continuous presence of human observers since 2004 (LC1, BT1, MK) or 2010 (LC2), so all animals are well habituated and individually recognized [Arlet et al., 2014]. In this study, we sampled 29 adult females: 15 with infants (named later 'mothers'- BT1: 4 infants, LC1: 6 infants, LC2: 3 infants, MK: 2 females, CC: 0 infants), and 14 females without infants (named later 'non-mothers' - BT1:1 female, LC1: 2 females, LC2: 2 females, MK: 2 females, CC: 7 females) at the time of the observations (i.e. 'non-mothers' are females that never had an infant or did not have any during the study). Eight females became mothers during the study (see complete list of mothers and infants in Table 1). Our research adhered to the American Society of Primatologists principles for the ethical treatment of primates.

[insert Table 1 here]

Females were initially individually identified by Chancellor [Chancellor \& Isbell, 2009a] and her field assistants (March 2004-July 2006) using natural markings such as relative body size, nipple color and size, and tail characteristics (scars, shape, and thickness of hair). We used the same characteristics to recognize maturing females (and males) as the years progressed. We knew approximate birth dates (within 6 weeks) for 13 adult females who matured and gave birth after 2004. We could also estimate birth months for two females who were still dependent on their mothers when our study began. Following Strum and Western 
[1982], and Arlet and colleagues [2015] criteria, we estimated the age of 14 females based on their relative body size, skin condition of perineal sexual swelling, nipple length, and general marks of aging, such as wrinkled skin on the face and the neck, saggy skin around the face, and thinning hair. Gray-cheeked mangabey females mature on average between 5 and 6.2 years, and give birth to their first infant on average between 6.8 and 7.8 years [Deputte, 1992; Arlet et al., 2014, 2015]. The mean gestation length is 175 days [Deputte, 1991].

Female dominance ranks were based on Arlet and colleagues [2014] using rank data from the 2011-2012 study period (Table 1). We recorded all dyadic agonistic interactions per group, including nonphysical threats (e.g., facial displays), approach-avoids (i.e., moving away from another who is approaching), supplants (i.e., taking the place of another), physical contacts (e.g., biting, tail-pulling, and pushing), and chases (i.e., aggressively pursuing another). We constructed dominance matrices for each study group (per year), with rank order determined by minimizing the number of reversals against the hierarchy (i.e., interactions below the diagonal). The rank of our mother subjects was very stable as no change was found when comparing the first and the second half of the study. We also characterized the parity of the female with the following number of infant: one (primiparous) and two, three, and four or more (multiparous).

In our study we included 15 offspring: 13 infants (up to 12 months) and two young juveniles, called later 'infants'. When a new infant was first seen in a group, we counted it as a birth and we began to collect call rates of its mother every month, during six months. Graycheeked mangabey infants are weaned at 6-7 months of age [Veromann, 2011]. During this study there were 10 male infants and 5 female infants (Table 1). The previous study showed that the infant mortality in the gray-cheeked mangabeys varies between 40 and $60 \%$ [Arlet et al. 2014]. 


\section{Behavioral Observations}

Two authors (MEA/ LLV) and the field assistant Richard Kaseregenyu (RK) collected data from July 2011 until March 2012 (MEA/ LLV July- September 2011, RK SeptemberDecember 2011 and MEA January-March 2012). Observers were trained by the same person and collected replicated data for comparisons (Spearman test: $\mathrm{R}=0.87, \mathrm{P}<0.001, \mathrm{~N}=620$ ). Observations were carried out in rotation between groups, with one group followed for six days every five weeks [Arlet et al., 2009].

In each group, every adult female (with and without infant) was followed using $90 \mathrm{~min}$ - focal sampling to record vocal behaviors. Each group was observed during six consecutive days per month and each day we tried to observe all females of the group (sometimes all females could not be found and therefore females differed in observation time). We repeated observations during six months, therefore each female was observed max. 36 times (6 days a month x 6 months). We collected 343 hours of focal observations, with a mean $\pm \mathrm{SD}=19.4 \pm$ $12.6 \mathrm{hr}$ per female.

Eight females gave birth during the study, therefore they were observed both as 'mothers' and 'non-mothers' -, and 14 females were observed as non-mothers only. The focal sampling order in each group was opportunistically determined by the first sighting of an adult female that had not yet been sampled during a particular day, while taking care to balance morning and afternoon sampling.

We recorded the occurrences of three call types: 1) contact calls (i.e. soft grunts) which are low-pitched and soft calls, composed of one or two units, emitted in affiliative and peaceful contexts; 2) excitement calls (i.e. staccato barks) which are two-unit, loud and highpitched calls, emitted at times of high arousal (e.g. important movements in the group, fights between group members); and 3) alarm calls (i.e. irk calls) which are single unit and highpitched calls emitted when a predator or an external danger is spotted [Chalmers, 1968]. 
Given their discrete acoustic structure, calls were easily recognizable without the need of acoustic recording. It was not possible to assess with certainty to whom calls were directed to, so this information was not scored. We recorded 1064 calls emitted by females with infants (average of $70.9 \pm 12.6$ calls per female) and 187 calls produced by females without infants (average of $1.5 \pm 2.8$ calls per female).

At the time of each call utterance, we also scored the mother-infant distance, when possible (i.e. for 505 of the 1064 calls, the rest of the time the infant was not visible or the habitat was too dense). We then categorized the distance at the time of each call using four classes (in meters): $0,0-5,5-10, \geq 10$.

\section{Statistical Analyses}

We performed all analyses using the statistical software STATISTICA 10 (StatSoft Inc. USA). We used generalized linear mixed models (GLMM), to test the influences on calling rates of mothers' (age in years, rank, and parity) and infants' (age in months and sex) characteristics. The dependent variable was the total number of calls recorded per month of observation (i.e. per month of infant age) divided by monthly observation time in minutes (to counterbalance the differences in sampling effort). The ranks and ages of the mothers and infants, both fixed factors, were considered as continuous factors, while parity (i.e. primiparous and multiparous) and infant sex were categorical factors. Infant identity and group identity were considered as random factors. The three call types (contact call, CC; excitement call, EX, and alarm call, AL) were tested separately using a GLM.

We used generalized linear mixed models (GLMM) to test the influence of motherinfant distance on call type. Here, the dependent variable was the distance at the time of each call utterance, and the call type (CC, EX, AL) was a categorical factor. Infant identity and group identity were considered as random factors. 
We also ran GLM to compare the calling frequency of female with infants and females without infants. Finally, when needed (CC/EX/AL call of mothers vs CC/EX/AL call of nonmothers), we applied the post hoc Fisher LSD test.

\section{Ethical Note}

All data were collected from habituated, wild animals without interfering with their activities. The research complied with the laws of Uganda and the protocols were approved by the Uganda Wildlife Authority and Uganda National Council for Science and Technology at the time the field research was conducted.

\section{RESULTS}

\section{Relation Between Having/Not-having an Infant and Call Rates}

Mothers produced on average 1.5 times more calls than non-mothers (GLMM: $\mathrm{df}=1, \mathrm{~F}=6.9$, $\mathrm{P}=0.009$; Figure 1). This was found for all call types sampled. Females with infants produced more contact calls (GLMM: $\mathrm{df}=1, \mathrm{~F}=4.7, \mathrm{P}=0.001)$, more excitement calls $(\mathrm{df}=1, \mathrm{~F}=6.8$, $\mathrm{P}=0.03)$ and more alarm calls $(\mathrm{df}=1, \mathrm{~F}=0.9, \mathrm{P}=0.01)$ than females without infants.

[insert Figure 1 here]

Overall, contact calls were the most frequent vocalizations emitted by mothers (68\%), followed by excitement calls (22.2\%), and alarm calls (5.7\%). Post hoc comparisons showed that mothers indeed produced more contact calls than excitement calls $(\mathrm{df}=1, \mathrm{~F}=48, \mathrm{P}<0.001)$ and alarm calls $(\mathrm{df}=1, \mathrm{~F}=101.6, \mathrm{P}<0.001)$, and more excitement calls than alarm calls $(\mathrm{df}=1$, $\mathrm{F}=8.1, \mathrm{P}=0.005)$ 


\section{Relation Between Mother and Infant Characteristics and Contact Call Rates}

The production of contact calls was influenced by infant age and sex but not by any characteristic of the mother (Table 2).

[insert Table 2 here]

Infant age was a determining factor of the mother's contact call frequencies (GLMM: $\mathrm{df}=1$, $\mathrm{F}=10.1, \mathrm{P}=0.003$; Table 2, Figure 2). The highest contact call rate was recorded for mothers with newborn infants (less than one month old). Later, during the first semester of infant's life, females decreased their contact call rate. Just after 6 months, contact call rates became high again and re-started to decrease significantly when the infant reached one year old. Overall mothers produced almost twice as many contact calls when they had daughters (GLMM: $\mathrm{df}=1, \mathrm{~F}=4.7, \mathrm{P}=0.04$; infant female: mean $\pm \mathrm{SD}=0.08 \pm 0.02$; infant male: mean \pm $\mathrm{SD}=0.05 \pm 0.04 ;$ Table 2)

[insert Figure 2 here]

\section{Relation Between Mother and Infant Characteristics and Excitement Call Rates}

While the mother's rank did not influence excitement call rates, younger and first-time mothers produced more excitement calls than older (GLMM: $\mathrm{df}=1, \mathrm{~F}=6.8, \mathrm{P}=0.01$; females of 7-8 yrs: $0.03 \pm 0.04$, females older than 9 yrs: $0.008 \pm 0.02$ ) and experienced mothers (GLMM: $\mathrm{df}=1, \mathrm{~F}=24.5, \mathrm{P}<0.001$; Table 2, Figure 3).

$$
\text { [insert Figure } 3 \text { here] }
$$

Then, while infant sex did not influence excitement call rates, the age of the infant had an impact on the excitement call rates: mothers of younger infants produced more excitement 
calls. In contrast to contact calls, the rate of excitement calls decreased constantly with infant age (GLMM: df=1, F=6, P=0.02; Figure 4).

[insert Figure 4 here]

\section{Relation Between Mother and Infant Characteristics and Alarm Call Rates}

Alarm call rates were independent of all maternal and infant characteristics (Table 2).

\section{Relation Between Call Type and Mother-infant Distance at the Moment of Call}

\section{Utterance}

Mother-offspring distance affected the rate of contact calls and excitement calls, but not alarm calls $(\mathrm{CC}$ calls: $\mathrm{df}=3, \mathrm{~F}=6.4, \mathrm{P}<0.001$; $\mathrm{EX}$ calls: $\mathrm{df}=3, \mathrm{~F}=5.7, \mathrm{P}=0.002 ; \mathrm{AL}$ calls: $\mathrm{df}=3, \mathrm{~F}=0.9$, $\mathrm{P}=0.42$; Figure 5). We found that contact calls increased in direct relation to the increase of the mother-offspring distance, whereas excitement calls were produced at the highest rate when the infant was held or carried by the mother. Alarm calls were totally independent of mother-infant distance.

$$
\text { [insert Figure } 5 \text { here] }
$$

\section{DISCUSSION}

Our study showed that both maternal and infant characteristics influenced the vocal behavior of females with young offspring, but in a call type-dependent way. Production of contact calls was dependent on infant age and infant sex. Also, contact call rates increased when the infant was further away. However, more excitement calls were found in young, first-time mothers and in mothers with younger infants, and more excitement calls were given while in physical contact with the infant. However, alarm calls were not influenced by any of these factors. We 
also found that mothers vocalized more frequently than females without infants, regardless of call types.

Some studies with different nonhuman primate species showed that contact call rates generally vary with the social experience of the female and notably her age and social status. However, this typically concerns their involvement in contact call exchanges and not systematically their overall contact call rate. For example, while growing older, adult females initiate more contact call exchanges [common marmosets Callithrix jacchus: Chen et al., 2009; Campbell's monkeys Cercopithecus campbelli: Lemasson et al., 2010; Japanese macaques Macaca fuscata: Lemasson et al., 2013]. In general, older and higher-ranked mothers, as experienced matriarchs, typically occupy a particular position in social networks in primates, being the center of a lot of social attention [de Waal, 1987; Furuichi, 1989; Idani, 1991; Henzi \& Barrett, 2002]. Female contact call exchange frequencies often depend on the size of their affiliative bonding networks [Japanese macaques: Arlet et al. 2015]. However, we found no influence of dominance rank on any of the call types sampled in this study. This may also be a consequence of the dynamic and flexible nature of female competitive relationships in gray-cheeked mangabeys within the same population (Chancellor \& Isbell, 2009b).

In addition we found that maternal experience also matters. Being a mother is thus an important factor as she calls much more than non-mother and this is particularly true for contact calls but interestingly with a non-random temporal pattern along the development of the infant. We did not score differently calls emitted alone and calls exchanged so there may be two explanations for the "two peaks" pattern observed. A first peak is found just after birth. We know that primate subadult and adult females are very attracted to newborn infants [Silk et al., 2002]. Contact calls are typically used frequently in this context in exchanges with approaching group members, to decrease possible aggressive reactions, and to facilitate 
allomothering [Chalmers, 1968; Silk, 2002]. The second peak corresponds to the time when infants start to move away frequently (at weaning age) and contact calls may be used in this context to maintain a socio-spatial cohesion with infants. We know that long-term social bonding is kin-biased in this species, as in baboons [Silk et al., 2006]. This socio-spatial hypothesis [Hemelrijk, 1999, 2002] is also supported by the fact that mother-infant distance has an impact on contact call emissions. Unlike alarm calls, contact calls do function to maintain spatial cohesion in a broad range of primate species, notably when bonded group members travel in a visually closed habitat [Koda et al., 2008], like the forest habitat of graycheeked mangabeys in Kibale. This is not limited to primates, dolphin mothers for instance also increase their whistles to help reunion as their infants get further away [Smolker et al., 1993]. The fact that alarm call rates were not related to any maternal or infant characteristic was to be expected because this call type has a habitat-dependent (non-social) function [see also Lemasson \& Hausberger, 2011; Bouchet et al., 2013].

We also found that infant sex had an impact on mother call usage, as mothers of female infants produced more contact calls than mothers of male infants. Mothers of infant females may give frequent contact calls to keep contact with them and to strengthen the bonds with them. In gray-cheeked mangabeys males migrate, but females stay in their natal group [Waser, 1977]. The matrilines play a key role when support is needed, so bonding with daughters is very important for females (more than with sons). Studies of maternal speech in humans showed that mothers talk to baby girls more frequently than to baby boys [Hoffman, 1977; Sung et al., 2013]. It is possible that early stimulation of communication by mothers with daughters may reinforce the male and female difference in the frequency of social calls, as in many species, the females are more 'talkative' than males [red-capped mangabeys Cercocebus torquatus: Bouchet et al., 2010] and rhesus monkeys [Macaca mulatta, Greeno \& Semple, 2009]. 
Another possibility is that variations in the vocal behavior of females were related to their internal arousal states. Internal state is known to influence call rates and is observed across a broad range of animal taxa from birds to primates [Leavesley \& Magrath, 2005; Dubois et al., 2009; Colonnello et al., 2010; Lemasson et al., 2012]. The fact that younger mothers, mothers of younger offspring and first-time mothers give more excitement calls and that the excitement call ratio decreases constantly with infant age (in contrast to contact calls) supports the arousal hypothesis [Schehka et al, 2007]. These females are known to be generally more anxious [Hooley, 1983]. The exaggerated anxiety of first-time mothers has been observed in a wide range of mammal species [e.g. elephants: Douglas-Hamilton \& Douglas-Hamilton, 1975; hanuman langurs Presbytis entellus: Hrdy, 1977] as they commonly overreact to infant behavior. The fact that excitement call rates were particularly high when the infant was in contact with its mother also supports this hypothesis.

To sum up, maternal vocal behavior of arboreal primates seems to be flexible, but complex, i.e. dependent on call social function. However, there is still a lot to discover. Therefore, long-term (developmental) studies are now needed to fully explore the social influence of maternal call usage on infant behavior. We acknowledge that a study with more individuals is also needed to clearly identify the relative importance of several factors. For example, parity and maternal age were related here; yet they were not equally influential (e.g. excitement calls are modulated by parity but not age). Lastly, we had no information about the identity of the receivers of the calls and a full interpretation would require more detailed observation of the social context of calling. 


\section{FUNDING}

This study was funded by "Mobilitas" postdoctoral grant (MJD56 to MEA), by the Estonian Research Council (institutional grant IUT34-8 to RM), and by the "Institut Universitaire de France" to AL.

\section{CONFLICT OF INTEREST}

We declare we have no conflict of interests.

\section{ACKNOWLEDGMENTS}

We thank the Uganda Wildlife Authority, Uganda National Council for Science and Technology, and personnel at the Makerere University Biological Field Station in Kanyawara for permission to work in Kibale National Park. We thank Kaseregenyu Richard for his dedicated work and invaluable assistance in the field. We thank Sophie Lumineau for early comments on the manuscript.

\section{REFERENCES}

Altmann J. 1980. Baboon mothers and infants. Cambridge, Harvard University Press.

Arlet ME, Grote MN, Isbell LA, Molleman F, Carey JR. 2009. Reproductive tactics influence cortisol levels in individual male gray-cheeked mangabeys (Lophocebus albigena). Hormones and Behavior 55: 210-216.

Arlet ME, Chancellor RL, Kaasik A, Chapman CA, Molleman F, Isbell LA, Mänd R, Carey JR. 2014. Maternal investment and infant survival in gray-cheeked mangabeys Lophocebus albigena. International Journal of Primatology 35: 476-490.

Arlet ME, Isbell LA, Kaasik A, Molleman F, Chancellor RL, Chapman CA, Mänd R, Carey JR. 2015. Determinants of reproductive success in female gray-cheeked mangabeys 
(Lophocebus albigena) in Kibale National Park, Uganda. International Journal of Primatology 36: 55-73.

Bardi M, Huffman MA. 2002. Effects of maternal style on infant behavior in Japanese macaques (Macaca fuscata). Developmental Psychology 41: 364-372.

Bouchet H, Pellier A, Blois-Heulin C, Lemasson A. 2010. Sex differences in the vocal repertoire of adult red-capped mangabeys (Cercocebus torquatus): a multi-level acoustic analysis. International Journal of Primatology 72: 360-375.

Bouchet H, Blois-Heulin C, Lemasson A. 2013. Social complexity parallels vocal complexity: a comparison of three nonhuman primate species. Frontiers in Psychology 4: 390 .

Brown $\mathrm{CH}$. 2014. The acoustic ecology of east African primates and the perception of vocal signals by gray-cheeked mangabeys and blue monkeys. In Dooling RJ, Hulse HS, editors. The comparative psychology of audition: perceiving complex sounds. Psychology Press. p. 201-239.

Chalmers N. 1968. The visual and vocal communication of free living mangabeys in Uganda. Folia Primatologica 9: 258-28.

Chancellor RL, Isbell LA. 2009a. Food site residence time and female competitive relationship in wild gray-cheeked mangabeys (Lophocebus albigena). Behavioural Ecology and Sociobiology 63: 1447-1458.

Chancellor RL, Isbell LA. 2009b. Female grooming markets in a population of gray-cheeked mangabeys (Lophocebus albigena). Behavioral Ecology 20: 79-86.

Chapman CA, Chapman LJ, Jacob AL, Rothman JM, Omeja P, Reyna-Hurtado R, Hartter J, Lawes MJ. 2010. Tropical tree community shifts: Implications for wildlife conservation. Biology and Conservation 143: 366-374. 
Chen H -C, Kaplan G, Rogers LJ. 2008. Contact calls of common marmosets (Callithrix jacchus): influence of age of caller on antiphonal calling and other vocal responses. American Journal of Primatology 71: 165-170.

Cheney DL, Seyfarth RM. 1990. How monkeys see the world: inside the mind of another species, University of Chicago Press, Chicago. P. 37-39.

Colonnello V, Iacobucci P, Newberry RC. 2010. Vocal and locomotor responses of piglets to social isolation and reunion. Developmental Psychobiology 52: 1-12.

Deputte B. 1991. Reproductive parameters of captive Grey-cheeked mangabeys. Folia Primatologica 57: 57-69.

Deputte B. 1992. Life history of captive Gray-cheeked mangabeys: physical and sexual development. International Journal of Primatology 13: 509-531.

De Waal FBM. 1987. Dynamics of social relationships. In Hinde RA, ed. Primate social relationships. Blackwell, Oxford. p.112-116.

Douglas-Hamilton I, Douglas-Hamilton O. 1975. Among the elephants. Viking, New York

Dubois A, Nowicki S, Searcy WA. 2009. Swamp sparrows, Melospiza georgiana, modulate vocal performance in an aggressive context. Biology Letters 5: 163-165.

Elowson AM, Snowdon CT, Sweet CJ. 1992. Ontogeny of trill and J-call vocalizations in the pygmy marmoset Cebuella pygmaea. Animal Behaviour 43: 703-715.

Fairbanks LA. 1996. Individual differences in maternal styles: Causes and consequences for mothers and off-spring. Advances in the Study of Behaviour 25: 579-611.

Furuichi T. 1989. Social interactions and the life history of femalePan paniscus in Wamba, Zaire. International Journal of Primatology 10: 173-197.

Greeno NC, Semple S (2009) Sex differences in vocal communication among adult rhesus macaques. Evolution and Human Behavior 30, 141-145

Gubbins C, McCowan B, Lynn SC, Hooper S, Reiss D. 1999. Mother-infant spatial relations 
in captive bottlenose dolphins, Tursiops truncatus. Marine Mammal Science 15: 751765.

Hammerschmidt K, Newman JD, Champoux M, Suomi SJ. 2000. Changes in rhesus macaque «coo » vocalizations during early development. Ethology 106: 873-886.

Hemelrijk CK. 1999. An individual-orientated model of the emergence of the despotic and egalitarian societies. Proceedings of the Royal Society of London B 266: 261-269.

Hemelrijk CK. 2002. Understanding social behaviour with the help of complexity science. Ethology 108: 655-671.

Henzi SP, Barrett L. 2002. Infants as a commodity in a baboon market. Animal Behaviour 63: 915-921.

Hinde R. 1974. Biological bases of human social behavior. McGraw-Hill, New York .

Hoffman LW 1977. Changes in family roles, socialization, and sex differences. American Psychologist 32, 644-657

Hoffman CL, Higham JP, Mas-Rivera A, Ayala JE, Maestripieri D. 2010. Terminal investment and senescence in rhesus macaques Macaca mulatta on Cayo Santiago. Behavioral Ecology 21: 972-978.

Hooley JM. 1983. Expressed emotion: A review of the critical literature. Clinical Psychology Review 5: 119-139.

Hrdy SB. 1977. The langurs of Abu. Harvard University Press, Cambridge.

Idani G. 1991. Social relationships between immigrant and resident bonobo (Pan paniscus) females at Wamba. Folia Primatologica 57: 83-95.

Koda H. 2004. Flexibility and context-sensitivity during the vocal exchange of coo calls in wild Japanese macaques (Macaca fuscata yakui). Behaviour 141: 1279-1296. 
Koda H, Shimooka Y, Sugiura H. 2008. Effects of caller activity and habitat visibility on contact call rate of wild Japanese macaques (Macaca fuscata). American Journal of Primatology 70: 1055-1063.

Koda H, Lemasson A, Oyakawa C, Rizaldi, Pamungkas J, Masataka N. 2013. Possible role of mother-daughter vocal interactions on the development of species-specific song in gibbons. PLoS ONE 8 .

Laporte MN, Zuberbühler K. 2011. The development of a greeting signal in wild chimpanzees. Developmental Science 14: 1220-34.

Leavesley AJ, Magrath RD. 2005. Communicating about danger: urgency alarm calling in a bird. Animal Behaviour 70: 365-373.

Lee PC. 1984. Ecological constraints on the social development of vervet monkeys. Behaviour 91: 245-261.

Lee P, Moss CJ. 1999. The social context for learning and behavioural development among wild African elephants. In Hilary O. Box, editor. Mammalian social learning: comparative and ecological perspectives. Cambridge University Press.

Lemasson A. 2011. What can forest guenons «tell » us about the origin of language? In Vilain A, Schwartz J-L, Abry C, Vauclair J, editors. Primate communication and human language: vocalisation, gestures, imitation and deixis in humans and non-humans. John Benjamins Publishing Company, Amsterdam. p. 39-70.

Lemasson A, Hausberger M. 2011. Acoustic variability and social significance of calls in female Campbell's monkeys (Cercopithecus campbelli campbelli). Journal of Acoustic Society of America 129: 3341-3352.

Lemasson A, Gandon E, Hausberger M. 2010. Attention to elders' voice in non-human primates. Biology Letters 6: 328 . 
Lemasson A, Remeuf K, Rossard A, Zimmermann E. 2012. Cross-taxa similarities in affectinduced changes of vocal behavior and voice in arboreal monkeys. PLoS ONE

Lemasson A, Guilloux M, Rizaldi, Barbu S, Lacroix A, Koda H. 2013. Age- and sexdependent contact call usage in Japanese macaques. Primates 54: 283-291.

Loy KM, Loy J. 1987. Sexual differences in early social development among captive patas monkeys. In Zucker E, editor. The comparative behavior of African monkeys. Alan R. Liss, New York.

Maestripieri D. 2005. Primate psychology. Harvard University Press, Cambridge.

Marler P. 1965. Communication in monkeys and apes. In De Vore I, ed. Primate behavior: field studies of monkeys and apes. Holt, Rinehart and Winston, New York. p. 544584.

Nash LT. 1978. The development of the mother-infant relationship in wild baboons Papio anubis. Animal Behaviour 26: 746-59.

Olupot W, Waser PM. 2001. Correlates of intergroup transfer in male grey-cheeked mangabeys. International Journal of Primatology 19: 169-187.

Olupot W, Waser PM. 2013. Lophocebus albigena Grey-cheeked mangabey. In Butynski TM, Kingdon J, Kalina J, editors. Mammals of Africa, vol. 2. Bloomsbury Press, London. p. 206-209.

Roush RS, Snowdon CT. 2001. Food transfer and development of feeding behavior and food-associated vocalizations in cotton-top tamarins. Ethology 107: 415-421.

Rosenblum LA, Youngstein KP. 1974. Developmental changes in compensatory dyadic response in mother and infant monkeys. In Lewis M, Rosenblum LA, editors. The effect of the infant on its caregiver. Wiley, New York. 
Schehka S, Esser K-H, Zimmermann E. 2007. Acoustical expression of arousal in conflict situations in tree shrews (Tupaia belangeri). Journal of Comparative Physiology A 193: $845-852$.

Silk JB. 2002. Grunts, girneys and good intentions: the origins of strategic commitment in Nonhuman Primates. In Nesse R, editor. Commitment: evolutionary perspectives. Russel Sage Press. p. 138-157.

Silk JB, Altmann J, Alberts SC. 2006. Social relationships among adult female baboons (Papio cynocephalus) I. Variation in the strength of social bonds. Behavioral Ecology and Sociobiology 61: 183-195.

Simpson MJA. 1985. Effects of early experience on the behaviour of yearling rhesus monkeys (Macaca mulatta) in the presence of a strange object: classification and correlation approaches. Primates 26: 57-72.

Smolker RA, Mann J, Smuts BB. 1993. Use of signature whistles during separations and reunions by wild bottlenose dolphin mothers and infants. Behavioural Ecology and Sociobiology 33: 393-402.

Struhsaker TT. 1971. Social behaviour of mother and infant vervet monkeys (Cercopithecus aethiops). Animal Behaviour 19: 233-250.

Strum SC, Western JD. 1982. Variation in fecundity with age and environment in olive baboons Papio anubis. American Journal of Primatology 3: 61-76.

Sung J, Fausto-Sterling A, Garcia Coll C, Seifer R (2013) The dynamics of age and sex in the development of mother-infant vocal communication between 3 and 11 months. Infancy $18,1135-1158$

Townsend SW, Deschner T, Zuberbühler K. 2008. Female chimpanzees use copulation calls flexibly to prevent social competition. PLOS One doi.org/10.1371/journal.pone.0002431 
Veromann LL. 2011. Maternal care in grey-cheeked mangabeys. Dissertation, University of Tartu, Estonia.

Wallis SJ. 1983. Sexual behaviour and reproduction of Cercocebus albigena johnstoni in Kibale Forest, western Uganda. International Journal of Primatology 4: 153-166.

Waser PM. 1977. Individual recognition, intragroup cohesion, and intergroup spacing: evidence from sound playback to forest monkeys. Behaviour 60: 28-74.

Waser PM, Brown CH. 1986. Habitat acoustics and primate communication. American Journal of Primatology 10: 135-164. 
Arlet et al. p. 24

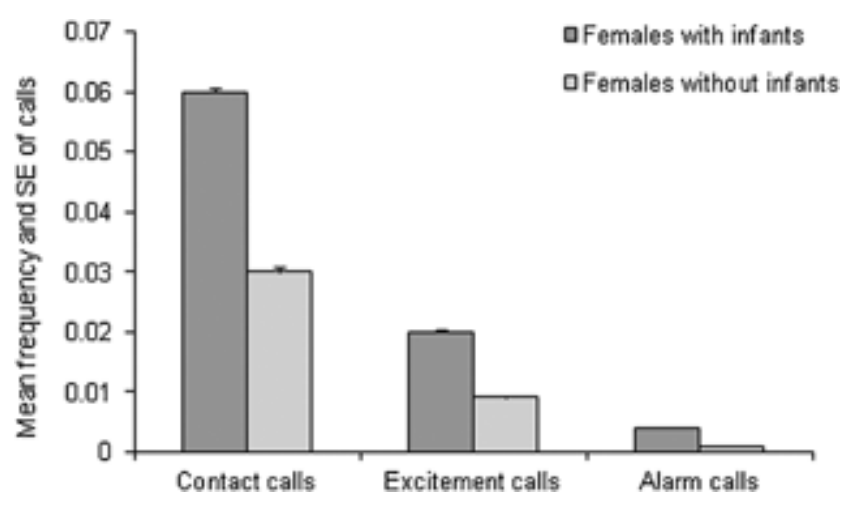


Arlet et al. p. 25




Arlet et al. p. 26

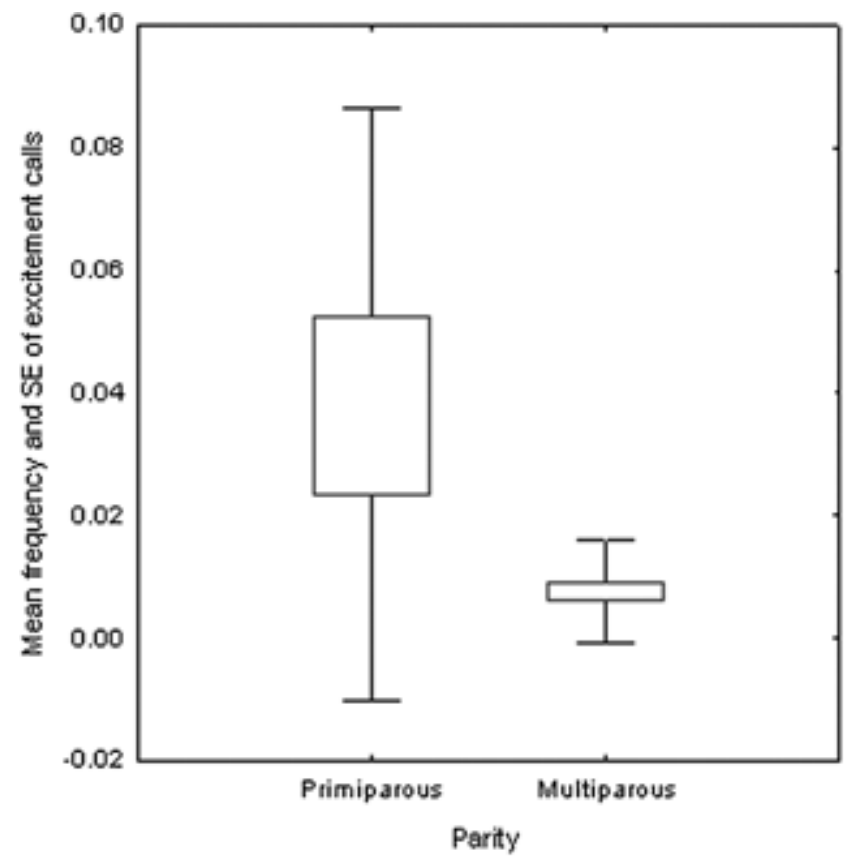


Arlet et al. p. 27

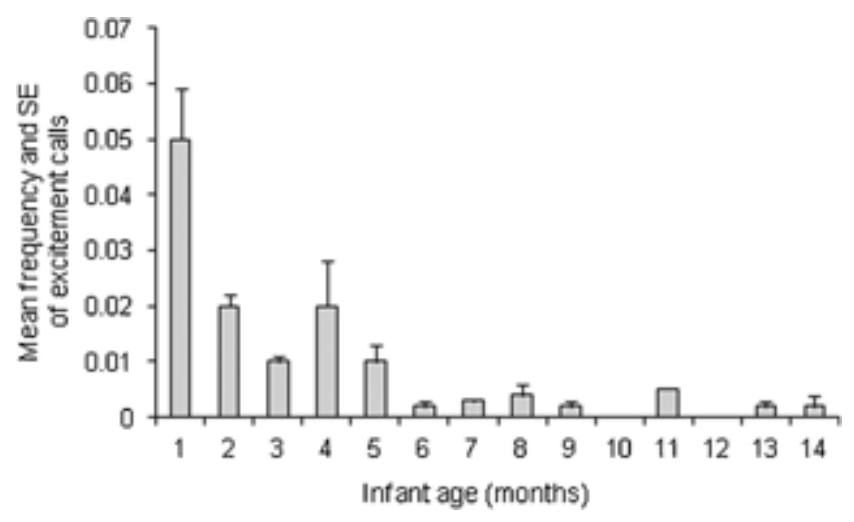


Arlet et al. p. 28

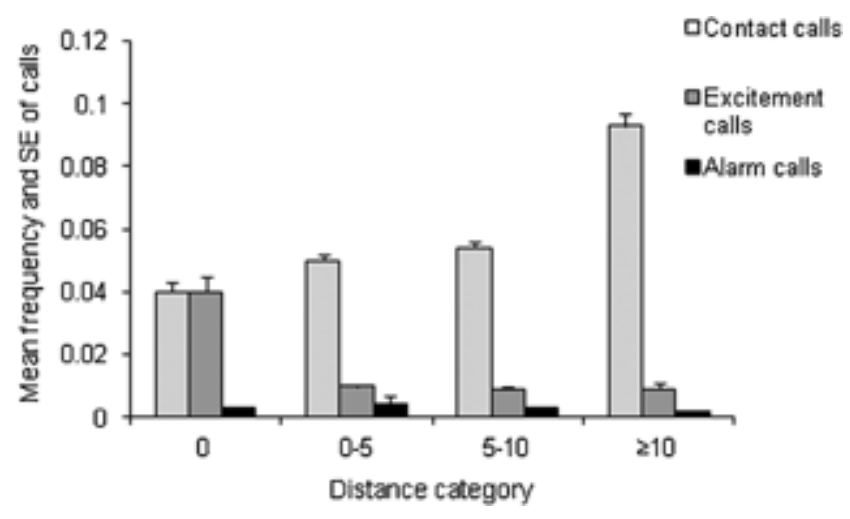




\section{FIGURE LEGENDS}

Figure 1. Relation between having/not-having an infant and call type usage. The number of calls represents mean monthly number of calls per minute (SE: Standard Error).

Figure 2. Relation between infant age and contact call usage. The number of calls represents mean monthly number of calls per minute (SE: Standard Error).

Figure 3. Relation between parity and excitement call usage. The number of calls represents mean monthly number of calls per minute (SE:

Standard Error).

Figure 4. Relation between infant age and excitement call usage. The number of calls represents mean monthly number of calls per minute (SE:

\section{Standard Error).}

Figure 5. Relation between call usage and the distance category. The distance was scored at the time of each call utterance (SE: Standard Error). 
TABLE I. Characteristics of Mothers and Infants in Five Study Groups of Gray-cheeked Mangabeys Studied Between 2011 and 2012 in Kibale National Park, Uganda.

\begin{tabular}{|c|c|c|c|c|c|}
\hline Group/Female & Age & Rank & Parity & $\begin{array}{c}\text { Infant } \\
\text { age }\end{array}$ & $\begin{array}{l}\text { Infant's } \\
\text { sex }\end{array}$ \\
\hline \multicolumn{6}{|l|}{ But1 } \\
\hline Kagezi* & 8 & 2 & $\mathrm{PF}$ & 0.5 & $\mathrm{~m}$ \\
\hline Kadogo & 10 & 3 & $\mathrm{MF}$ & 0.5 & $\mathrm{f}$ \\
\hline Mwirima* & 7 & 4 & $\mathrm{MF}$ & 4 & $\mathrm{~m}$ \\
\hline Muhimbo & 7 & 7 & $\mathrm{PF}$ & 5 & $\mathrm{~m}$ \\
\hline Kibogo & 20 & 8 & $\mathrm{MF}$ & - & - \\
\hline \multicolumn{6}{|l|}{ LC1 } \\
\hline Nyakato & 14 & 1 & $\mathrm{MF}$ & 9 & $\mathrm{~m}$ \\
\hline Nsungwa & 11 & 2 & $\mathrm{MF}$ & 15 & $\mathrm{~m}$ \\
\hline Kiiki & 14 & 3 & MF & 14 & $\mathrm{~m}$ \\
\hline Ngonzi* & 9 & 5 & MF & 4 & $\mathrm{f}$ \\
\hline Namara* & 11 & 6 & MF & 4 & $\mathrm{f}$ \\
\hline Kaisiki* & 9 & 7 & MF & 4 & $\mathrm{~m}$ \\
\hline Kabogo & 13 & 8 & MF & - & - \\
\hline Kadome & 6 & 4 & - & - & - \\
\hline \multicolumn{6}{|l|}{ LC2 } \\
\hline Kiiki2 & 13 & 1 & $\mathrm{MF}$ & 9 & $\mathrm{~m}$ \\
\hline Kissa2 & 8 & 2 & PF & 10 & $\mathrm{~m}$ \\
\hline Tindereya* & 12 & 4 & $\mathrm{MF}$ & 5 & $\mathrm{~m}$ \\
\hline Bikoma & 8 & 3 & - & - & - \\
\hline Mihira & 8 & 5 & - & - & - \\
\hline \multicolumn{6}{|l|}{ MK } \\
\hline Kakende* & 12 & 1 & $\mathrm{MF}$ & 0.5 & $\mathrm{f}$ \\
\hline Broom* & 8 & 2 & $\mathrm{PF}$ & 0.5 & $\mathrm{f}$ \\
\hline Worm & 8 & 3 & - & - & - \\
\hline Nyiambo & 18 & 4 & $\mathrm{MF}$ & - & - \\
\hline \multicolumn{6}{|l|}{$\mathrm{CC}$} \\
\hline Barango & 13 & 1 & $\mathrm{MF}$ & - & - \\
\hline Kituku & 18 & 2 & $\mathrm{MF}$ & - & - \\
\hline Kabere & 18 & 3 & $\mathrm{MF}$ & - & - \\
\hline Kigezi & 7 & 4 & - & - & - \\
\hline Kirungi & 8 & 5 & $\mathrm{PF}$ & - & - \\
\hline Muzaire & 19 & 6 & $\mathrm{MF}$ & - & - \\
\hline Kabatoro & 10 & 7 & $\mathrm{PF}$ & - & - \\
\hline
\end{tabular}


* Females that were observed both as mothers and non-mothers. Age of females is given in years and age of infants in months (at the end of the study). Age of the females older than 10 years was estimated. Parity represents: primiparous females (PF; first-time mothers) and multiparous females (MF; experienced mothers). No information about parity (-) indicates females that had not yet given birth. Infant sex: male (m), female (f). No information about infant age and sex (-) indicates that females had no infant at the time of observations ("nonmother'). 
TABLE II. Relation Between Contact call/Excitement call/Alarm Call Rates and MotherInfant Characteristics. Results of GLMM test with Group and Infant Identity as Random Effects.

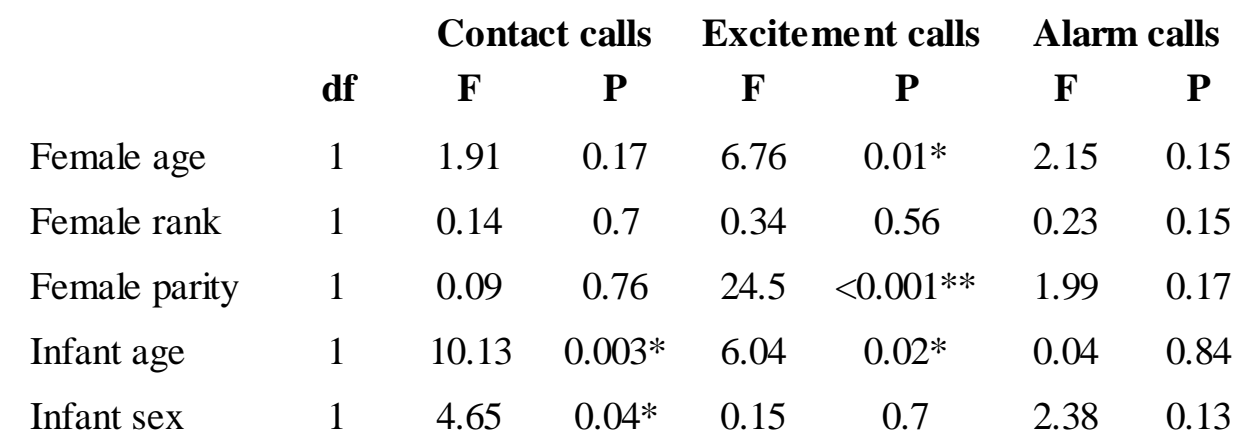

* Significant at $\alpha=0.05, * *$ Significant at $\alpha=0.001$ 